\title{
RHEOLOGY IN AUSTRALIA AND NEW ZEALAND
}

\begin{abstract}
T the Jubilee Conference of the Australian and New Zealand Association for the Advancement of Science, held at the University of Sydney during August 20-24, a Sub-Section on Rheology was created by members of the New South Wales Branch of the British Society of Rheology, under the secretaryship of Dr. L. Dintenfass (Department of Medicine, University of Sydney) and under the presidency of Prof. R. C. L. Bosworth (Department of Physical Chemistry, the University of New South Wales). This was the first time that rheologists had been able to form a definite group within a general conference in Australasia. Some twenty-seven papers were presented to actively interested audiences.

At the opening session the president pointed out that rheology had had a particularly long pre-scientific incubation period prior to the development of scientific principles, thought and instrumentation. In Australia and New Zealand rheological principles are involved in many primary and secondary industrial activities in medicine, agriculture and engineering, but, at the moment, there is in these countries no tertiary education course devoted to the study, the teaching or the research in rheological principles as such. The time is surely coming when this omission must be made good. The address at this session was given by Mr. R. S. T. Kingston, officer-in-charge of the Timber Physics Section, Division of Forest Products, C.S.I.R.O., South Melbourne, Victoria. Mr. Kingston reviewed the historical development in rheological theory with particular emphasis on nonlinear phenomenological theory and non-colinear stress arising from non-linear strain velocities. Mr. Kingston was equally concerned with thermodynami-
\end{abstract} cal and statistical interpretations.

A session was devoted to rheology in biological systems. Dr. M. C. M. Dodgson (Prince of Wales Hospital, Randwick, N.S.W.) gave a paper on the rheology of brain, in which the mechanical properties of brain cell material were considered. Dr. Dintenfass gave a paper on viscosity and thixotropy of blood, and Dr. A. A. Palmer (Sydney Hospital) on the flow of blood in capillaries. The viscosity of blood decreases as the rate of shear increases; the viscosity of blood samples remains nearly constant at relatively higher rates of shear. Abnormal blood may show thixotropy even at these relatively higher rates of shear. Acceleration and deceleration in branching capillaries can lead to segregation of blood cells from plasma. Dr. B. Bloch (Sydney Hospital) and Dr. G. W. Hastings (Department of Polymer Science, the University of New South Wales) gave two papers on the use of plastics and adhesives in bone fractures.

A number of papers was concerned with the rheological properties of natural products. The rheology of protein solutions was considered by Dr. A. G. Parts (Department of Physical Chemistry, University of Sydney), who based his measurements on the dielectrie loss and the viscosity of amino-acid solutions. Mr. M. Feughelman (Division of Textile Physics, C.S.I.R.O., North Ryde, N.S.W.) gave a paper on the structure and the mechanical properties of wool and related the properties with the nature of a number of bonds holding polypeptide chains together. Dr. B. J. Rigby (Division of Textile Physics, C.S.I.R.O., North Ryde, N.S.W.) gave a paper on thermal transitions in collagen. The transition temperature of wet unconstrained material apparently correlates with the amount of hydroxyproline present in the collagen. Mr. F. C. H. Ottaway (Bread Research Institute, North Ryde, N.S.W.) presented a paper on the rheology of bread dough. Initial fermentation changes the properties of the gluten content and no entirely satisfactory methods are available in dough-testing machines.

A number of papers was presented on the subject of the rheology of wood and wood products. Dr. M. C. Probine (Dominion Physical Laboratory, D.S.I.R., Lower Hutt, New Zealand) presented a paper on the rheological and morphological properties of plant cells. Mr. L. D. Armstrong (Division of Forest Products, C.S.I.R.O., South Melbourne, Victoria) considered the effects of moisture change on the creep of wood. Both the strength and the modulus of elasticity of wood decrease as the moisture content is decreased. Mr. H. G. Higgins (Division of Forest Products, C.S.I.R.O., South Melbourne, Victoria) gave a paper on the structural rheology of pulp and paper, and Prof. M. Chaikin (School of Textile Technology, the University of New South Wales) gave one on the rheology of non-uniform fibres, with special reference to textile fibres subjected to longitudinal extension.

The extension of rheological principles to chemical engineering problems and the more customary uses of these principles and the assessment of properties of the products of chemical industry were considered in a number of papers. Dr. T. Hagyard (Department of Chemical Engineering, University of Canterbury, Christchurch, New Zealand) gave a paper on the viscosity of fluidized bed systems, which he illustrated by showing high-speed photographs and high-speed cinematographic records of very nearly uniform spheres. The structures shown were those of hexagonal structures over limited regions with structure. less intergranular materials and with occasional 'holes'. Mr. A. Sherwood (Department of Mechanical Engineering, University of Sydney) gave a paper on the determination of stresses in gelatine models. The newer silicone plastics are also being investigated for their suitability for this purpose. Mr. R. E. Price (Central Research Laboratory, Imperial Chemical Industries, Australia and New Zealand, Ltd., Ascot Vale, Victoria) gave a paper on post-extrusion swelling in thermoplastic melts, and Dr. F. Connors (Department of Polymer Science, University of New South Wales) gave one on the rheological characteristics of polyvinyl chloride. Mr. K. R. Hall (Chemical Research Laboratories, C.S.I.R.O., Fishermen's Bend, Victoria) gave a paper on the mixing operations of non-Newtonian fluids.

A number of papers was concerned with the basic properties of certain classes of materials, and others outlined new techniques of instrumentation. Mr. D. R. Axelrad (Department of Mechanical Engineering, University of Sydney), for example, gave a paper on the flow of metals, in which he outlined presentday theories of high-temperature creep. Dr. R. 
Tanner (Department of Mechanical Engineering, University of Sydney) gave a paper on non-Newtonian lubricants. Greases and those systems which approximate in their behaviour to Bingham solids give higher bearing friction than Newtonian lubricants. Mr. A. W. Findlay (Monash University, Clayton, Victoria) gave a paper on the rheology of pigment suspensions and outlined a modified Bingham approach to the properties of these systems. Mr. R. Bell (Taubmans Industries, Ltd., St. Peters, N.S.W.) gave a paper on normal stresses in fluids, and stressed the need for emphasis on truly accurately level surfaces. Changing strain velocities can give rise to large normal stresses in many systems, including glycerine and golden syrup.

Dr. H. A. J. Battaerd (Central Research Labora. tory, Imperial Chemical Industries, Australia and
New Zealand, Ltd., Ascot Vale, Victoria) gave an account of a high-speed cinematic record of the performance of an impact tester utilizing a falling sphere which was applied to polythene films. Dr, P. U. A. Grossman (Division of Forest Products, C.S.I.R.O., South Melbourne, Victoria) outlined some unconventional testing methods in the study of creep and vibrational properties of solids.

The Sub-Section held one conjoint meeting with the Pharmaceutical Sciences Section. Two papers were presented, one by Dr. L. Dintenfass on microrheological methods and techniques, and one by Prof. R. C. L. Bosworth on the rheological properties of emulsions. The papers were followed by a panel discussion in which the hosts expressed many ways in which the rheologists could be of help to them.

R. C. L. Bosworth

\section{THE BRITISH GELATINE AND GLUE RESEARCH ASSOCIATION}

$\mathrm{T}$ HE twenty-third research panel meeting of the British Gelatine and Glue Research Association was held in London on May 23. The chairman of the Association, Mr. S. G. Hudson (Richard Hodgson and Sons, Beverley), who presided, directed attention to the Association's wide range of interests as reflected in the programme for the day.

The first paper, "The Chemical Nature of Elastin", was contributed by Dr. S. M. Partridge (Low Temperature Research Station, Cambridge). The identification, occurrence, physical properties and isolation of elastin were reviewed. The ease of removal of other proteins from elastin varies with the tissue concerned, but even with the ligamentum nuchae of cattle, autoclaving is necessary. It is recognized that some structural changes are possible during isolation; nevertheless, severo damage is unlikely since there is only $1 \mathrm{~g}$ mole of $N$-terminal residue per $350,000 \mathrm{~g}$ of the isolated protein. The isolated protein is readily broken down into fragments by treatment with acids and the fragments are clearly multichain, indicating the existence of cross-links in the original protein. Enzymatically degraded elastin was chromatographed to give a coloured peptide believed to be the 'core' of the elastin structure. The 'core' gives, on acid hydrolysis, at least four substances of some complexity and these are being examined. The discussion centred round the nature and significance of the 'core'.

In the second paper, Mr. J. A. Mackenzio (R. and P. Schorer, Slough) described "The Manufacture of Gelatine Capsules by the Rotary Die Process". Sheots of plasticized gelatine gel are fed on to a pair of revolving dios and the capsules are automatically filled and sealed on the die. The process calls for a high standard of precision engineering and also for considerable ingenuity in using the unique physical properties of gelatine to the best advantage. Given these factors, capsules of a great variety of shapes and sizes can be made at very high throughput-rates and with a considerable degree of automation.

Dr. R. N. Coleman (Geo. Nelson, Dale, Warwick) gave the third paper, entitled "The Dispersion of Concentrated Gelatine Gels in Hot Syrups". Sometimes high-grade gelatines are encountered which prove to be difficult to disperse in hot, concentrated sugar solutions when using the usual method of soaking the gelatine in water and then adding it as a swollen gel. The difficulty can be minimized by completely dissolving the gelatine in hot water before addition to the syrup: the grist size of the gelatine is important in assisting easy solution in this mothod. Even so, a fow gelatines remain which cannot be dispersed unless the amount of water in the system is increased.

The final paper, "The Cross-linking of Glues with Epoxy Compounds and Formaldehyde Donors", by J. A. Gibbs, I. R. Whiteside and J. Wootton (British Gelatine and Glue Research Association), was presented by Mr. I. R. Whiteside. There has been a general desire to get away from formaldehyde as a cross-linking agent for animal glues because it is toxic and unpleasant to handle. There is a need also for cross-linking agents which can be mixed with glue to give compositions of reasonable pot-life and which can be cured to insolubility after application. It was shown that these requirements could be met by using either dimethylol urea as a donor of formaldehyde in solution or an epoxy resin.

D. A. SuTroN

\section{EDUCATION OF TECHNICIANS AND TECHNOLOGISTS}

\begin{abstract}
$\mathrm{A}^{\mathrm{N}}$ $\mathrm{N}$ international conference on this topic was held in Cracow, Poland, during September 6-10,1961, to discuss the education and further training of technical personnel.

The conference was initiated by the Association of Engineers of the General Technical Federation of Poland (Scientific World, 6, No. 1; 1962). The
\end{abstract}

Associations of Engineers and Ministries of Higher Education of Czechoslovakia, the German Democratic Republio, Yugoslavia, Poland, Hungary and the Soviet Union also took part in the organization of the conference. Representatives of the Prague Regional Centre of the World Federation of Scientific Workers and of the Higher Schools and Scientific Institutes 